\title{
Silica-Supported PdGa Nanoparticles: Metal Synergy for Highly Active and Selective $\mathrm{CO}_{2}$-to- $\mathrm{CH}_{3} \mathrm{OH}$ Hydrogenation
}

Scott R. Docherty, Nat Phongprueksathat, Erwin Lam, Gina Noh, Olga V. Safonova, Atsushi Urakawa, and Christophe Copéret*

Cite This: JACS Au 2021, 1, 450-458

Read Online

ACCESS |

山ll Metrics \& More

回 Article Recommendations

S1 Supporting Information

ABSTRACT: The direct conversion of $\mathrm{CO}_{2}$ to $\mathrm{CH}_{3} \mathrm{OH}$ represents an appealing strategy for the mitigation of anthropogenic $\mathrm{CO}_{2}$ emissions. Here, we report that small, narrowly distributed alloyed $\mathrm{PdGa}$ nanoparticles, prepared via surface organometallic chemistry from silica-supported $\mathrm{Ga}{ }^{\mathrm{III}}$ isolated sites, selectively catalyze the hydrogenation of $\mathrm{CO}_{2}$ to $\mathrm{CH}_{3} \mathrm{OH}$. At $230{ }^{\circ} \mathrm{C}$ and $25 \mathrm{bar}$, high activity $\left(22.3 \mathrm{~mol}_{\mathrm{MeOH}} \mathrm{mol}_{\mathrm{Pd}}{ }^{-1} \mathrm{~h}^{-1}\right)$ and selectivity for $\mathrm{CH}_{3} \mathrm{OH} / \mathrm{DME}$ (81\%) are observed, while the corresponding silica-supported Pd nanoparticles show low activity and selectivity. X-ray absorption spectroscopy (XAS), IR, NMR,

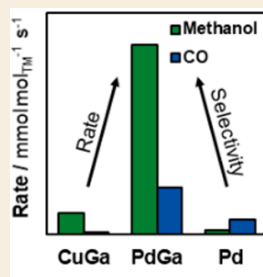
High Performance - High activity - High selectivity

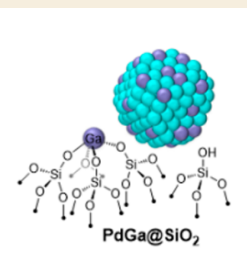

Precise Synthesis - Tailored precursor - $<2 \mathrm{~nm}$ nanoparticles

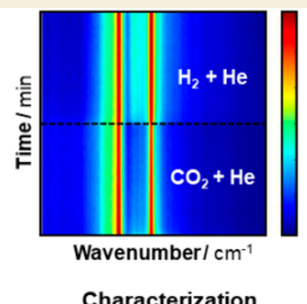

- PdGa alloy (XAS/TEM)

- Surface species (DRIFTS) and scanning transmission electron microscopy-energy-dispersive

$\mathrm{X}$-ray provide evidence for alloying in the as-synthesized material. In situ XAS reveals that there is a dynamic dealloying/realloying process, through Ga redox, while operando diffuse reflectance infrared Fourier transform spectroscopy demonstrates that, while both methoxy and formate species are observed in reaction conditions, the relative concentrations are inversely proportional, as the chemical potential of the gas phase is modulated. High $\mathrm{CH}_{3} \mathrm{OH}$ selectivities, across a broad range of conversions, are observed, showing that $\mathrm{CO}$ formation is suppressed for this catalyst, in contrast to reported Pd catalysts.

KEYWORDS: $\mathrm{CO}_{2}$ hydrogenation, Heterogeneous catalysis, Alloys, Nanoparticles, Operando spectroscopy, Hydrogenation

\section{INTRODUCTION}

The conversion of $\mathrm{CO}_{2}$ to liquid fuels has garnered significant attention in recent years, as a strategy to mitigate anthropogenic $\mathrm{CO}_{2}$ emissions and an alternative source of platform chemicals to fossil fuels. ${ }^{1}$ In particular, the direct hydrogenation of $\mathrm{CO}_{2}$ to $\mathrm{CH}_{3} \mathrm{OH}$ (eq 1-Scheme 1a) has been highlighted as an appealing target. ${ }^{2-5}$ For this purpose, metallic nanoparticles supported on oxide supports, modified with various promoters, have been extensively studied. For the most part, efforts have focused on copper particles combined with zinc oxide/alumina $\left(\mathrm{Cu} / \mathrm{ZnO} / \mathrm{Al}_{2} \mathrm{O}_{3}\right)^{6-8}$ or supported on zirconia $\left(\mathrm{Cu} / \mathrm{ZrO}_{2}\right){ }^{5,9-11}$ However, these $\mathrm{Cu}$-based catalysts show limited activity, decreasing selectivity with increasing conversion, and suffer from deactivation. ${ }^{12}$ Therefore, alternative metals, oxide promoters, and supports have been investigated. ${ }^{5}$ In this context, Pd-containing systems (Pd/ $\left.\mathrm{MO}_{x}\right)^{13-18}$ show superior activities to those based on $\mathrm{Cu}$ in the hydrogenation of $\mathrm{CO}_{2}$ to $\mathrm{CH}_{3} \mathrm{OH}$ when supported on reducible oxides $\left(\mathrm{ZnO}\right.$ or $\left.\mathrm{Ga}_{2} \mathrm{O}_{3}\right)$. In particular, $\mathrm{Pd}-\mathrm{Ga}$-based systems have attracted attention in recent years, as highly active catalysts for the hydrogenation of $\mathrm{CO}_{2}$ to methanol. ${ }^{13,14,19-23}$ These systems, based on $\mathrm{Pd} / \mathrm{Ga}_{2} \mathrm{O}_{3}, \mathrm{Pd}-\mathrm{Ga} /$ $\mathrm{SiO}_{2}, \mathrm{Pd} / \mathrm{Ga}_{2} \mathrm{O}_{3} / \mathrm{SiO}_{2}$, or PdGa colloidal nanocrystals, often show superior activity when compared to $\mathrm{Cu}$-based catalysts. However, Pd-based catalysts display low $\mathrm{CH}_{3} \mathrm{OH}$ selectivity
Scheme 1. (a) Thermodynamics of $\mathrm{CO}_{2}$ Hydrogenation. (b) Comparison of Reported Pd/Ga Systems and This Work
a) $\mathrm{CO}_{2}+3 \mathrm{H}_{2} \rightleftharpoons \mathrm{CH}_{3} \mathrm{OH}+\mathrm{H}_{2} \mathrm{O}$
$\mathrm{CO}_{2}+\mathrm{H}_{2} \rightleftharpoons \mathrm{CO}+\mathrm{H}_{2} \mathrm{O}$

$$
\begin{aligned}
& \Delta_{r} \mathrm{H}_{230 \mathrm{C}}=-62 \mathrm{~kJ} \mathrm{~mol}^{-1} \quad \text { (1) } \\
& \Delta_{\mathrm{r}} \mathrm{H}_{230 \mathrm{C}}=40 \mathrm{~kJ} \mathrm{~mol}^{-1} \quad \text { (2) }
\end{aligned}
$$

b)
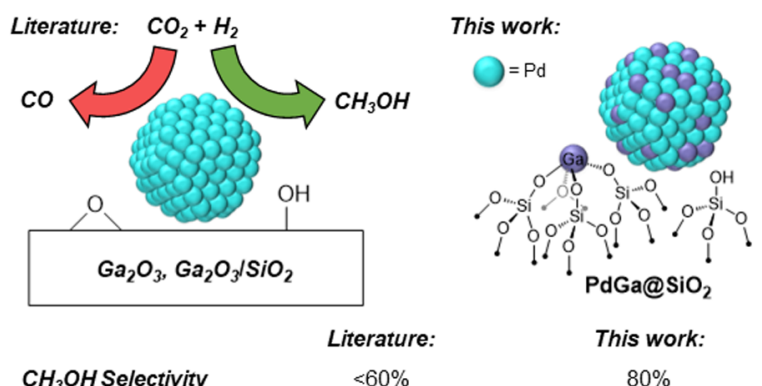

$\mathrm{CH}_{3} \mathrm{OH}$ Selectivity

$<60 \%$

Nature of Gall'

III-defined $\mathrm{Ga}_{2} \mathrm{O}_{3}$

Ga-silicate

$\mathrm{GaO}_{x}$ clusters Pd-Ga alloying-dealloying

Received: January 18, 2021

Published: March 17, 2021

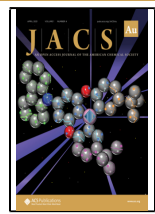


Table 1. Physicochemical Properties of Reduced Materials

\begin{tabular}{|c|c|c|c|c|c|c|c|}
\hline material & EA,wt \% & $\begin{array}{l}\text { particle } \\
\text { size, }^{a} \mathrm{~nm}\end{array}$ & $\begin{array}{l}\mathrm{CO} \text { chemisorption, }^{b} \\
\mathrm{~mol}_{\mathrm{CO}} \mathrm{mol}_{\mathrm{Pd}}{ }^{-1}\left(\bigoplus_{\mathrm{CO}}\right)\end{array}$ & $\begin{array}{l}\mathrm{H}_{2} \text { chemisorption, } \\
\text { mol }_{\mathrm{H} 2} \mathrm{~mol}_{\mathrm{Pd}}{ }^{-1}\end{array}$ & $\begin{array}{l}\mathrm{H} / \mathrm{CO} \\
\text { ratio }\end{array}$ & $\begin{array}{l}\text { terminal } \mathrm{CO} \\
\text { stretch, } \mathrm{cm}^{-1}\end{array}$ & $\begin{array}{l}\text { bridging } \mathrm{CO} \\
\text { stretch, } \mathrm{cm}^{-1}\end{array}$ \\
\hline PdGa@SiO 2 & $\begin{array}{l}\text { Pd: } 1.08 \\
\text { Ga: } 1.66\end{array}$ & $1.6 \pm 0.4$ & $0.55(55 \%)$ & 0.56 & 2.0 & 2086 & 1960 \\
\hline $\mathrm{Pd} @ \mathrm{SiO}_{2}$ & Pd: 1.61 & $1.6 \pm 0.3$ & $0.61(61 \%)$ & 0.91 & 3.0 & 2094 & 1967 \\
\hline
\end{tabular}

a)
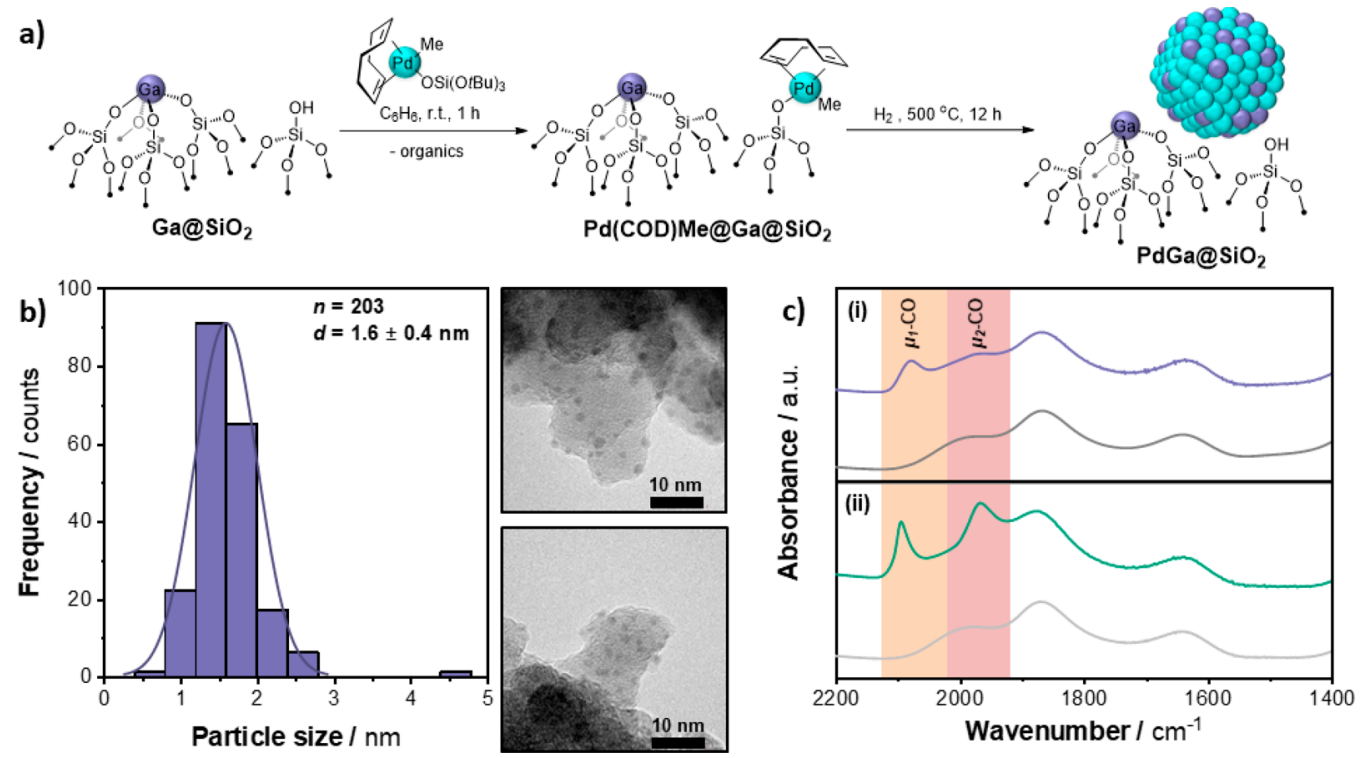

Figure 1. (a) Synthetic procedure for PdGa@SiO 2 . (b) Particle size distribution and representative TEM images for $\mathrm{PdGa}_{2} @ \mathrm{SiO}_{2}$; and (c) CO-

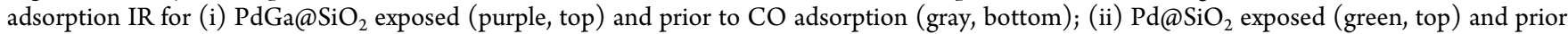
to $\mathrm{CO}$ adsorption (gray, bottom). $10 \mathrm{mbar} \mathrm{CO}$.

$(<60 \%$, Scheme $1 \mathrm{~b})$ due to the competing reverse water gas shift (RWGS) reaction (eq 2). ${ }^{13,21}$ As such, molecular insights into the origin of the high activity of these systems as well as the underlying cause of the undesired RWGS reaction is critical to the design of improved $\mathrm{CO}_{2}$ hydrogenation catalysts.

Our group has recently shown that surface organometallic chemistry (SOMC) can be an ideal approach to control metal-support interfaces and to improve the catalytic performance for various reactions including $\mathrm{CO}_{2}$ hydrogenation. $^{24-28}$ We thus reasoned that SOMC could provide a tool to tune the $\mathrm{CO}_{2}$ hydrogenation activity and selectivity of $\mathrm{Pd}$ by tailoring the interface between Pd and Ga. Herein, we report the synthesis of a bimetallic PdGa system, consisting of small PdGa alloy nanoparticles generated by grafting a tailored $\mathrm{Pd}$ molecular precursor, $\mathrm{Pd}(\mathrm{COD}) \mathrm{Me}\left(\mathrm{OSi}\left(\mathrm{O}^{t} \mathrm{Bu}\right)_{3}\right)$ (1) ( $\mathrm{COD}=1,5$-cyclooctadiene), on the silanol sites of silicacontaining isolated $\mathrm{Ga}^{\mathrm{III}}$ sites $\left(\mathrm{Ga} @ \mathrm{SiO}_{2}\right),{ }^{29}$ followed by reduction under $\mathrm{H}_{2}$. This material (PdGa@SiO 2 , Scheme 1b), characterized by transmission electron microscopy (TEM), chemisorption, X-ray absorption spectroscopy (XAS), energy-dispersive X-ray (EDX) mapping as well as CO-adsorption infrared (IR) spectroscopy, shows high activity and unprecedented selectivity in the hydrogenation of $\mathrm{CO}_{2}$ to $\mathrm{CH}_{3} \mathrm{OH}$ when compared to reported Pd-containing catalysts and conventional $\mathrm{Cu}$-based systems. The $\mathrm{PdGa}$ nanoparticles undergo partial dealloying under $\mathrm{CO}_{2}$ hydrogenation as confirmed by XAS, but Pd remains metallic throughout the reaction, and $\mathrm{Ga}$ is partially oxidized but remains highly dispersed. The absence of large domains of $\mathrm{Ga}_{2} \mathrm{O}_{3}$, which are known to promote the RWGS (forming $\mathrm{CO}$ ), probably explains the high methanol selectivity. ${ }^{30}$ An analysis of strongly bound surface adsorbates by nuclear magnetic resonance (NMR) spectroscopy and IR suggests the presence of mostly methoxy moieties. Transient operando diffuse reflectance infrared Fourier transform spectroscopy (DRIFTS) and multivariate curve resolution (MCR) analyses show that methoxy and carbonyl species are preferentially stabilized under $\mathrm{CO}_{2}$-rich conditions, while formate moieties are only detected under $\mathrm{H}_{2}$-rich conditions. These observations parallel the alloying-dealloying of PdGa, indicating that the catalyst is highly dynamic, with implications for its reactivity and selectivity in $\mathrm{CO}_{2}$ hydrogenation.

\section{RESULTS AND DISCUSSION}

\section{Synthesis and Characterization of Supported Materials}

We first developed a tailored Pd precursor that is amenable to grafting on silica and nanoparticle formation while releasing all its organic ligands: $\mathrm{Pd}(\mathrm{COD}) \mathrm{Me}\left(\mathrm{OSi}(\mathrm{O} t \mathrm{Bu})_{3}\right), \mathbf{1}$ (Supporting Information S2 and S3). We first evaluated the grafting of 1 on silica dehydroxylated at $700{ }^{\circ} \mathrm{C}\left(\mathrm{SiO}_{2-700}, 0.26 \mathrm{mmol}-\mathrm{OH}\right.$ $\mathrm{g}^{-1}$ ) that affords a monografted complex, (三SiO)Pd(COD)$\mathrm{Me}$, with a concomitant liberation of 0.8 equiv of $\mathrm{HOSi}$ $(\mathrm{O} t \mathrm{Bu})_{3}$ per Pd (Supporting Information S4). An IR analysis of the grafted material (Supporting Information S5) reveals the emergence of $\mathrm{C}-\mathrm{H}$ stretching (3100-2700 $\left.\mathrm{cm}^{-1}\right)$ and bending (1700-1300 $\left.\mathrm{cm}^{-1}\right)$ bands, alongside a decreased intensity for the isolated $\equiv \mathrm{SiOH}$ band at $3747 \mathrm{~cm}^{-1}$, indicative of grafting through silanol groups. ${ }^{13} \mathrm{C}$ crosspolarization magic-angle spinning (CP-MAS) NMR (Support- 

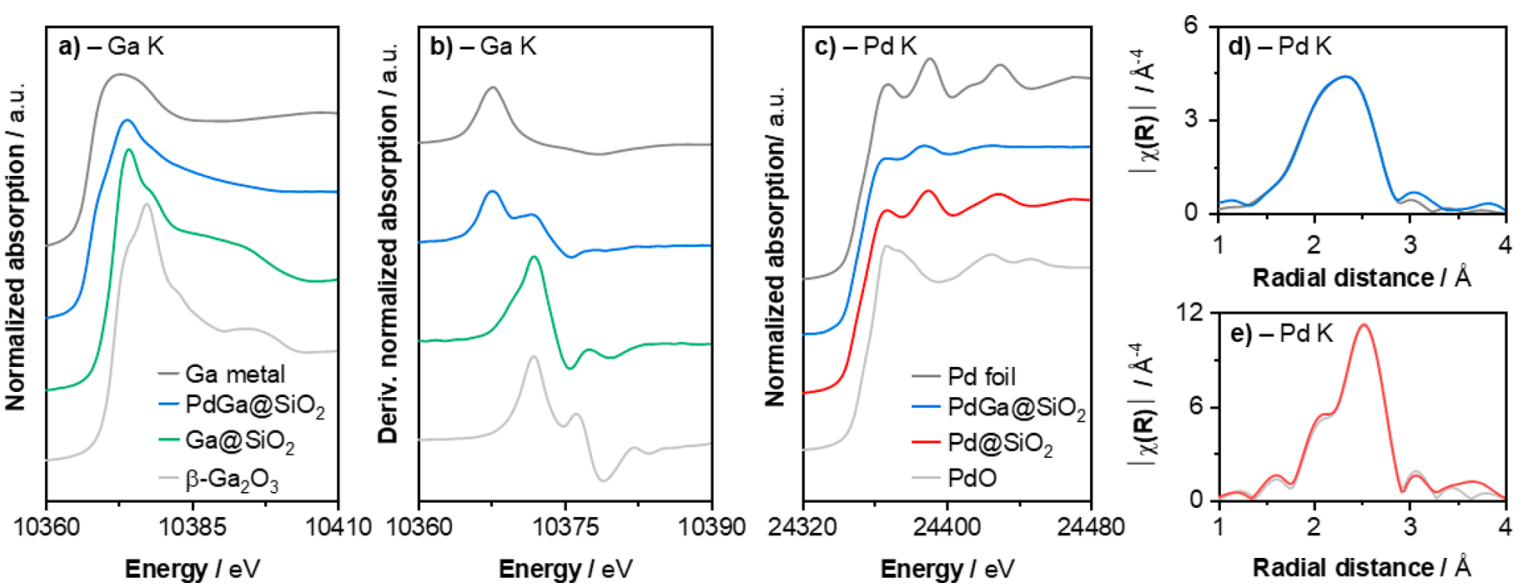

Figure 2. Normalized XANES spectra for (a) Ga K edge, (b) first derivative Ga K edge-Ga metal (dark gray), $\mathrm{PdGa}_{2} @ \mathrm{SiO}_{2}(\mathrm{blue}), \mathrm{Ga}_{2} @ \mathrm{SiO}_{2}$ (green), and $\beta-\mathrm{Ga}_{2} \mathrm{O}_{3}$ (light gray); (c) $\mathrm{Pd} \mathrm{K}$ edge-Pd foil (dark gray), $\mathrm{PdGa} @ \mathrm{SiO}_{2}$ (blue), $\mathrm{Pd} @ S i O_{2}$ (red), and $\mathrm{PdO}$ (light gray); and $\mathrm{Pd} \mathrm{K}$ edge EXAFS fits (d) PdGa@SiO 2 and (e) $\mathrm{Pd@SiO} 2$ ( $k$-weight: 3 , fit in light gray).

ing Information S5) shows signals at 126, 94, 30, 27, and 11 $\mathrm{ppm}$, which is consistent with the spectrum of the molecular precursor. The signals at 126 and 94 ppm are assigned to C-sp ${ }^{2}$ carbons of COD lying trans- to Me and OSi $\equiv$, respectively. ${ }^{31}$ The peak at $11 \mathrm{ppm}$ is assigned to $\mathrm{Pd}-\mathrm{Me}$, which is consistent with a displacement of the large $(t \mathrm{BuO})_{3} \mathrm{SiO}-$ ligand by a surface siloxy ligand upon grafting. Reduction under a flow of $\mathrm{H}_{2}(1 \mathrm{bar})$ at $500{ }^{\circ} \mathrm{C}$ yields $\mathrm{Pd}$ nanoparticles with a size of 1.6 $\pm 0.4 \mathrm{~nm}$, as shown by TEM, while IR reveals the reemergence of the isolated silanol band, alongside the disappearance of all bands associated with organic ligands (Supporting Information S5). $\mathrm{H}_{2}$ and $\mathrm{CO}$ chemisorption show an uptake of $0.91 \mathrm{~mol}_{\mathrm{H} 2} \mathrm{~mol}_{\mathrm{Pd}}{ }^{-1}$ and $0.61 \mathrm{~mol}_{\mathrm{CO}} \mathrm{mol}_{\mathrm{Pd}}{ }^{-1}$, respectively (Table 1 , Supporting Information S6). Considering a $1: 1 \mathrm{CO} / \mathrm{Pd}$ stoichiometry, ${ }^{32}$ the dispersion from $\mathrm{CO}$ chemisorption $\left(\nexists_{\mathrm{CO}}\right)$ equals $61 \%$, in a reasonable agreement with the dispersion from TEM $\left(\bigoplus_{\mathrm{TEM}} \approx 70 \%\right.$; Supporting Information S9). ${ }^{32}$ While $\mathrm{H}_{2}$ chemisorption is not effective for a determination of the metal dispersion of Pd nanoparticles due to the formation of a stable bulk hydride with larger particles $(>2.6 \mathrm{~nm}),{ }^{32}$ a comparison of the $\mathrm{H}_{2}$ uptake and $\oplus_{\mathrm{CO}}$ would correspond to approximately three hydrogen atoms per surface Pd.

With these encouraging results in hand, the molecular precursor (1) was next grafted on $\mathrm{Ga} @ \mathrm{SiO}_{2}$ (Figure 1a), a surface-doped silica prepared via SOMC that contains $0.8 \mathrm{Ga}$ $\mathrm{nm}^{-2}$, to generate a grafted material, $\mathrm{Pd}(\mathrm{COD}) \mathrm{Me} @ \mathrm{Ga} @ \mathrm{SiO}_{2}$. In this case, 1.9 equiv of isobutene per Pd (quantified by NMR, Supporting Information S4) was evolved during grafting. The formation of isobutene in place of $\operatorname{HOSi}(\mathrm{O} t \mathrm{Bu})_{3}$ is consistent with the presence of Lewis acid sites, which catalyze the decomposition of $\mathrm{HOSi}(\mathrm{O} t \mathrm{Bu})_{3} \cdot{ }^{29}$ An IR analysis of the grafted material reveals the emergence of $\mathrm{C}-\mathrm{H}$ stretching and bending bands, alongside a decreased intensity for the isolated $\equiv \mathrm{SiOH}$ band (Supporting Information S5), indicative of grafting through the silanol groups. The elemental analysis of the grafted material indicates the presence of 11 equiv of $\mathrm{C}$ and 25 equiv of $\mathrm{H}$ per $\mathrm{Pd}$, in agreement with the proposed structure (Supporting Information S4). Furthermore, the ${ }^{13} \mathrm{C}$ CP-MAS NMR shows signals at 126, 95, 29, 20, and 11 ppm (Supporting Information S5), consistent with a chemical environment akin to that of the molecular precursor and the surface species grafted on silica; that is, the chemical shift of the olefinic protons and carbons confirms that all surface species are $\mathrm{Pd}^{\mathrm{II}}$ with a methyl and a siloxy ligand. Treatment under a flow of $\mathrm{H}_{2}(1 \mathrm{bar})$ at $500{ }^{\circ} \mathrm{C}$ yields nanoparticles with a size of $1.6 \pm 0.3 \mathrm{~nm}$, as shown by TEM (Figure $1 \mathrm{~b}$ ), while $\mathrm{H}_{2}$ and $\mathrm{CO}$ chemisorption show an uptake of $0.56 \mathrm{~mol}_{\mathrm{H} 2} \mathrm{~mol}_{\mathrm{Pd}}{ }^{-1}$ and $0.55 \mathrm{~mol}_{\mathrm{CO}} \mathrm{mol}_{\mathrm{Pd}}{ }^{-1}\left(\oplus_{\mathrm{CO}}=55 \%\right.$, Table 1, Supporting Information S6). The $\mathrm{H}_{2}$ uptake, which corresponds to two $\mathrm{H}$ per surface $\mathrm{Pd}$, is significantly lower than the three $\mathrm{H}$ per surface Pd than that observed for $\mathrm{Pd} @ \mathrm{SiO}_{2}$, despite the nearidentical particle size according to TEM, and suggests a different electronic structure of $\mathrm{Pd}$ in the presence of Ga. Furthermore, the transmission IR of a self-supporting pellet of PdGa@SiO ${ }_{2}$ exposed to a pressure of $\mathrm{CO}(10 \mathrm{mbar})$ at room temperature reveals a strong vibrational band at $2086 \mathrm{~cm}^{-1}$ and a much weaker band at $1960 \mathrm{~cm}^{-1}$, assigned to a terminally bound $\mathrm{CO}$ on $\mathrm{Pd}\left(\mu_{1}-\mathrm{CO}_{\mathrm{Pd}}\right)$ and bridged $\mathrm{CO}$ species $\left(\mu_{2}-\right.$ $\mathrm{CO}_{\mathrm{Pd}}$ ), respectively (Figure 1c, Supporting Information S7). This observation contrasts with what is observed for $\mathrm{Pd} @ \mathrm{SiO}_{2}$, where two bands of similar intensity at 2094 and $1967 \mathrm{~cm}^{-1}$ are attributed to terminal and bridging species, ${ }^{16,33}$ and is consistent with the formation of a PdGa alloy, where the presence of a bridging $\mathrm{CO}$ species is suppressed through a dilution of surface Pd species. ${ }^{34}$ This disparity highlights the intrinsic difference in the interaction of the particles with $\mathrm{CO}$, which can be explained by the dilution of surface Pd by $\mathrm{Ga}^{0}$ centers. Furthermore, the red-shifted terminal $\mathrm{CO}$ bands (ca. 8 $\mathrm{cm}^{-1}$ ) observed for the bimetallic system provides further evidence for alloying. ${ }^{34,35}$

To gain a greater understanding of the structure of the assynthesized materials, XAS was performed. For PdGa@SiO Ga $\mathrm{K}$ edge X-ray absorption near edge structure (XANES) shows two edge features (identified by the two maxima of the first derivative at 10367.5 and $10371.8 \mathrm{eV}$, Figure 2a,b, Supporting Information S8), indicating the presence of two distinct species-one metallic, at an energy typical for $\mathrm{Ga}(0)$, and one $\mathrm{Ga}^{\mathrm{III}}$ with an edge energy typical of tetracoordinate $\mathrm{Ga}$ sites. ${ }^{36}$ The absence of any species with the energy expected for octahedral $\mathrm{Ga}$ sites indicates that the material formed does not correspond to bulk $\mathrm{Ga}_{2} \mathrm{O}_{3}$-an observation that contrasts with materials prepared using impregnation techniques. ${ }^{13,14}$ The linear combination fit (LCF) of the XANES indicates a ratio of 67:33 for the two species (metallic/oxidic, Supporting Information S8). This ratio is consistent with the formation of 
a Ga-rich alloyed phase. The corresponding Pd K edge XANES (Figure 2c, Supporting Information S8) shows a strong shift to lower energy for PdGa@SiO $2(24348.1 \mathrm{eV})$ from that of bulk Pd $(24350.0 \mathrm{eV})$, while a smaller shift is observed for Pd@ $\mathrm{SiO}_{2}(24348.8 \mathrm{eV})$, consistent with earlier literature describing the edge energy of supported Pd nanoparticles. ${ }^{32}$

An in situ study of the reduction process, by XAS-TPR (temperature-programmed reduction $\left(\mathrm{H}_{2}\right)$ ) at the $\mathrm{Pd} \mathrm{K}$ edge, in combination with an MCR analysis, indicates that $\mathrm{Pd}^{\mathrm{II}}$ in $\mathrm{Pd}(\mathrm{COD}) \mathrm{Me} @ \mathrm{Ga} @ \mathrm{SiO}_{2}$ is reduced to $\mathrm{Pd}^{0}$ under a flow of $\mathrm{H}_{2}$ at room temperature (Supporting Information S8, Figures S27-S30), highlighting the facile reduction of the molecular precursor employed. Conversely, $\mathrm{Ga}$ is gradually reduced and intercalated into palladium nanoparticles as temperature is increased (vide infra), as evidenced by a continuous measurement of both the Ga K and Pd K edges (see Supporting Information S8, Figures S31-S39). Ga $\mathrm{K}$ edge XANES (Figures S35-S36) indicates that the formation of a metallic Ga species occurs, while MCR analysis indicates that this is a gradual process (Figure S37). MCR analysis of the corresponding $\mathrm{Pd} \mathrm{K}$ edge XANES, measured in identical conditions, demonstrates that changes occur simultaneously for Pd (Figure S33), indicating that the reduction and intercalation of $\mathrm{Ga}$ occur in unison (see the Supporting Information S8 for an extended discussion).

An analysis of the extended X-ray absorption fine structure (EXAFS) region was also performed. $\mathrm{PdGa} @ \mathrm{SiO}_{2}$ was fitted with $\mathrm{Pd}-\mathrm{Ga}$ scattering path $(N=2.8 \pm 0.9, R=2.48 \pm 0.02$ $\AA)$ and Pd-Pd path $(N=3.1 \pm 0.9, R=2.73 \pm 0.01 \AA)$, providing further evidence for the formation of an alloy with 1:1 Pd/Ga stoichiometry (Figure 2d, Supporting Information S8). For comparison, the Pd K edge EXAFS for $\mathrm{Pd} @ \mathrm{SiO}_{2}$ was fitted with a $\mathrm{Pd}-\mathrm{Pd}$ scattering path (Figure $2 \mathrm{e}, N=8.1 \pm 0.4$, $R=2.73 \pm 0.002 \AA)$.

The emergence of a feature consistent with $\mathrm{Ga}^{0}$ in the $\mathrm{Ga} \mathrm{K}$ edge XANES as well as EXAFS fitting at the Pd $\mathrm{K}$ edge indicate that an alloy forms upon reduction under $\mathrm{H}_{2}$. Furthermore, STEM-EDX mapping indicates the coexistence of $\mathrm{Pd}$ and $\mathrm{Ga}$ in the nanoparticles, in agreement with the observed configuration from XAS (Supporting Information S9). Overall, the CO adsorption IR, XAS, and EDX show that intimate domains of $\mathrm{Pd}$ and $\mathrm{Ga}$, in the form of a PdGa alloy, are present upon reduction of the grafted material at $500{ }^{\circ} \mathrm{C}$.

\section{Catalytic Performance}

The catalytic performance of PdGa@SiO 2 and $\mathrm{Pd@SiO}$ was then evaluated in the hydrogenation of $\mathrm{CO}_{2}$ to $\mathrm{CH}_{3} \mathrm{OH}$ (3:1:1 $\mathrm{H}_{2} / \mathrm{CO}_{2} / \mathrm{Ar}, 25$ bar, $230{ }^{\circ} \mathrm{C}$ ) (Figure 3, Table 2, Supporting Information S10). For PdGa@SiO $\mathrm{mmol}_{\mathrm{MeOH}+\mathrm{DME}} \mathrm{mol}_{\mathrm{Pd}}{ }^{-1} \mathrm{~s}^{-1}$ was observed, while $\mathrm{Pd} @ \mathrm{SiO}_{2}$ displays a much lower intrinsic rate for $\mathrm{CH}_{3} \mathrm{OH}(0.14 \mathrm{mmol}$ $\left.\mathrm{mol}_{\mathrm{Pd}}{ }^{-1} \mathrm{~s}^{-1}\right)$. Under the same conditions, $\mathrm{Ga} @ \mathrm{SiO}_{2}$ is inactive. The catalyst slowly deactivates $(25 \%)$ over $36 \mathrm{~h}$ on stream. Note also that the $\mathrm{CH}_{3} \mathrm{OH}$ formation rate is ca. 1 order of magnitude greater for $\mathrm{PdGa} @ \mathrm{SiO}_{2}$ than for $\mathrm{Cu}$-based reference catalysts (Table 2). ${ }^{11,27}$ In addition to an increased rate, the PdGa@SiO ${ }_{2}$ system displays a significantly increased $\mathrm{CH}_{3} \mathrm{OH}$ selectivity ( $81 \%$ vs $20 \%$ for $\mathrm{Pd} @ \mathrm{SiO}_{2}$ ). The large difference in selectivity and activity between PdGa@SiO 2 and the parent monometallic materials highlights the remarkable synergistic effect of $\mathrm{Pd}$ and $\mathrm{Ga}$. In addition, the high $\mathrm{CH}_{3} \mathrm{OH}$ selectivity with $\mathrm{PdGa} @ \mathrm{SiO}_{2}$ does not decrease markedly as conversion increases (ca. $75 \%$ selective for methanol at $4 \%$
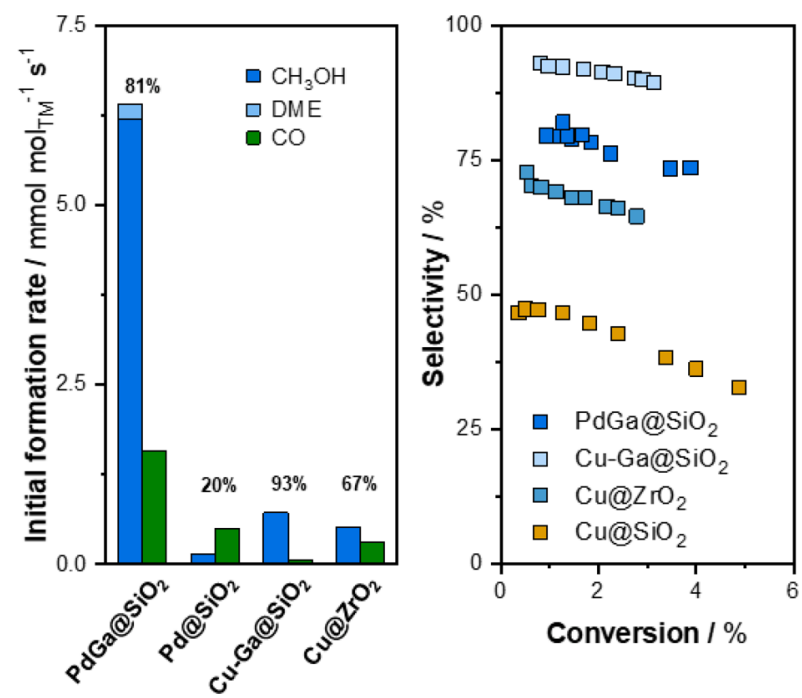

Figure 3. (left) Formation rates for $\mathrm{PdGa} @ \mathrm{SiO}_{2}, \mathrm{Pd} @ \mathrm{SiO}_{2}, \mathrm{Cu}-$ $\mathrm{Ga} @ \mathrm{SiO}_{2}$, and $\mathrm{Cu} @ \mathrm{ZrO}_{2}$. (right) Selectivity as a function of conversion for PdGa@SiO $, \mathrm{Cu}-\mathrm{Ga} @ \mathrm{SiO}_{2}, \mathrm{Cu} @ \mathrm{SiO}_{2}, \mathrm{Cu} @ \mathrm{ZrO}_{2}$. Conditions: $3: 1: 1 \mathrm{H}_{2} / \mathrm{CO}_{2} / \mathrm{Ar}, 25 \mathrm{bar}, 230{ }^{\circ} \mathrm{C}, 200 \mathrm{mg}$ of catalyst, $5 \mathrm{~g}$ of $\mathrm{SiC}, 6-100 \mathrm{sccm}$.

Table 2. Summary of Formation Rates and Selectivities for Materials Investigated, Alongside Reference Data for Materials Previously Tested in the Same Conditions

\begin{tabular}{|c|c|c|c|c|}
\hline \multirow[b]{2}{*}{$\begin{array}{c}\text { material } \\
(\text { wt\% } \mathrm{Pd} / \mathrm{Cu})\end{array}$} & \multicolumn{3}{|c|}{$\begin{array}{l}\text { formation rate, } \mathrm{mmol} \mathrm{s}^{-1} \mathrm{~mol} \\
\qquad \mathrm{Pd} / \mathrm{Cu}\end{array}$} & \multirow{2}{*}{ 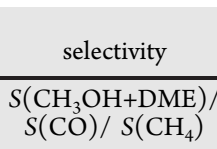 } \\
\hline & $\underset{\mathrm{DME}^{a}}{\mathrm{CH}_{3} \mathrm{OH}+}$ & $\mathrm{CO}$ & $\mathrm{CH}_{4}$ & \\
\hline $\begin{array}{l}\mathrm{PdGa} @ \mathrm{SiO}_{2} \\
(1.08)\end{array}$ & 6.40 & 1.57 & $<0.01^{b}$ & $81 / 19 / \mathrm{n} / \mathrm{a}$ \\
\hline $\begin{array}{l}\mathrm{Pd} @ \mathrm{SiO}_{2} \\
(1.61)\end{array}$ & 0.14 & 0.50 & 0.03 & $20 / 75 / 5$ \\
\hline $\mathrm{Ga} @ \mathrm{SiO}_{2}(\mathrm{n} / \mathrm{a})$ & $\mathrm{n} / \mathrm{a}^{b}$ & $\mathrm{n} / \mathrm{a}^{b}$ & $\mathrm{n} / \mathrm{a}^{b}$ & $\mathrm{n} / \mathrm{a}$ \\
\hline $\begin{array}{l}\mathrm{Cu} @ \mathrm{SiO}_{2}{ }^{c} \\
(4.5)\end{array}$ & 0.23 & 0.24 & $<0.01^{b}$ & $49 / 51 / n / a$ \\
\hline $\begin{array}{l}\mathrm{Cu} @ \mathrm{ZrO}_{2}{ }^{c} \\
(2.33)\end{array}$ & 0.51 & 0.30 & $\mathrm{n} / \mathrm{a}$ & $67 / 33 / \mathrm{n} / \mathrm{a}$ \\
\hline $\begin{array}{l}\mathrm{CuGa@SiO}{ }_{2}^{c} \\
(3.88)\end{array}$ & 0.72 & 0.06 & $\mathrm{n} / \mathrm{a}$ & $93 / 7 / \mathrm{n} / \mathrm{a}$ \\
\hline
\end{tabular}

${ }^{a}$ Conditions: $3: 1: 1\left(\mathrm{H}_{2} / \mathrm{CO}_{2} / \mathrm{Ar}\right), 25 \mathrm{bar}, 230{ }^{\circ} \mathrm{C}, 200 \mathrm{mg}$ of catalyst, $5 \mathrm{~g}$ of $\mathrm{SiC}, 6-100 \mathrm{sccm}$. Normalized by mole carbon. n/a indicates not applicable. ${ }^{b}$ Below the detection limit of the thermal conductivity detector/flame ionization detector. ${ }^{c}$ Previously reported under the same conditions. ${ }^{11,27}$

conversion, Figure 3), in contrast to $\mathrm{Cu} / \mathrm{ZrO}_{2}$ or $\mathrm{Cu} / \mathrm{ZnO}$ / $\mathrm{Al}_{2} \mathrm{O}_{3}$, where a significant drop in selectivity is observed as conversion increases (Table S7). ${ }^{5}$ This increased $\mathrm{CH}_{3} \mathrm{OH}$ selectivity at higher conversion was already observed in the related $\mathrm{Cu}-\mathrm{Ga} @ \mathrm{SiO}_{2}$ system ( 90\%) prepared via SOMC, though the latter shows ca. 1 order of magnitude lower $\mathrm{CH}_{3} \mathrm{OH}$ formation rates $\left(0.72 \mathrm{mmol}_{\mathrm{MeOH}} \mathrm{mol}_{\mathrm{Cu}}{ }^{-1} \mathrm{~s}^{-1}\right){ }^{27}$

\section{In Situ and Postreaction Catalyst States}

To assess changes to $\mathrm{PdGa} @ \mathrm{SiO}_{2}$ under reaction conditions, the material was first analyzed after the reaction. The TEM of $\mathrm{PdGa} @ \mathrm{SiO}_{2}$ after the reaction reveals that the particle size does not change after the reaction $(1.6 \pm 0.4 \mathrm{~nm}$, Figure S11), indicating that the as-synthesized material does not sinter significantly under reaction conditions. Similarly, the XANES of the spent catalyst $\left(\mathrm{PdGa} @ \mathrm{SiO}_{2}\right)$ indicates no significant 
changes in the edge energy or the white line intensity for the Pd K edge (24348.0 eV vs $24348.1 \mathrm{eV}$ ), while the Ga K edge XANES reveals the presence of both a metallic component and a Ga ${ }^{\mathrm{II}}$ component (10367.2 and $10371.5 \mathrm{eV}$, Supporting Information S11). The LCF of the $\mathrm{Ga} \mathrm{K}$ edge gives a $\mathrm{Ga}^{0} / \mathrm{Ga}^{\mathrm{III}}$ ratio of 46:54, suggesting that part of the alloyed gallium is oxidized under reaction conditions. Notably, the oxidized Ga appears to be exclusively tetracoordinated Ga (Supporting Information S8 and S11). The absence of octahedral Ga sites, typical of $\mathrm{Ga}_{2} \mathrm{O}_{3}$, is consistent with the formation of highly dispersed $\mathrm{Ga}$ sites or small $\mathrm{GaO}_{x}$ clusters upon the segregation of $\mathrm{Pd}$ and $\mathrm{Ga}$ from the alloy present in the as-synthesized material. The absence of bulk $\mathrm{Ga}_{2} \mathrm{O}_{3}$ is also consistent with the low formation rate and selectivity for $\mathrm{CO}$, which can readily occur on $\mathrm{Ga}_{2} \mathrm{O}_{3}$ via RWGS. ${ }^{30}$ A study of the material, by Ga K edge XANES under a flow of $\mathrm{H}_{2} / \mathrm{CO}_{2}\left(5 \mathrm{bar}, 230{ }^{\circ} \mathrm{C}\right)$, demonstrates that the material undergoes a partial oxidation under reaction conditions, which is demonstrated by both the increase in the white line intensity and the partial disappearance of the feature at $10367.5 \mathrm{eV}$ (Supporting Information S11 Figures S54 and S55). The change is, however, reversible; under $\mathrm{H}_{2}$ at $230{ }^{\circ} \mathrm{C}$, a partial rereduction of a proportion of tetracoordinate $\mathrm{Ga}$ is observed, as evidenced by the re-emergence of the feature at $10367.5 \mathrm{eV}$ (Supporting Information S11 Figures S56 and S57), highlighting the dynamic nature of the dealloying/realloying process for this material.

\section{Study of Bound Surface Adsorbates and Reaction Intermediates}

To further understand the divergent reactivity of the monoand bimetallic systems, the nature of surface adsorbates was probed by IR and NMR spectroscopy.PdGa@SiO 2 and Pd@ $\mathrm{SiO}_{2}$ were contacted with a $\mathrm{H}_{2} / \mathrm{CO}_{2}$ mixture $(3: 1)$ at $230{ }^{\circ} \mathrm{C}$ for $12 \mathrm{~h}$ in a high-pressure glass reactor at 5 bar. When cooled, volatiles were removed under reduced pressure, and the solid was analyzed by transmission IR (Figure 4). Analysis of the IR spectrum of the exposed PdGa@ $\mathrm{SiO}_{2}$ shows the emergence of peaks at 2996, 2959, 2857, and $1466 \mathrm{~cm}^{-1}$, assigned to surface methoxy species (Supporting Information S12). PdGa@SiO was also contacted with a $\mathrm{H}_{2} /{ }^{13} \mathrm{CO}_{2}$ mixture $(3: 1)$ at $230{ }^{\circ} \mathrm{C}$ for $12 \mathrm{~h}$ in a high-pressure glass reactor at 5 bar. ${ }^{13} \mathrm{C} \mathrm{CP-MAS}$, ${ }^{1} \mathrm{H}$ MAS, and ${ }^{1} \mathrm{H}-{ }^{13} \mathrm{C}$ heteronuclear correlation (HETCOR)

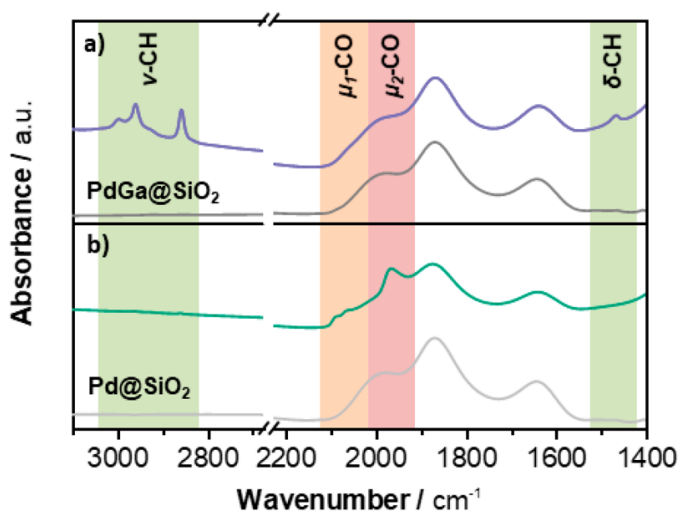

Figure 4. IR analysis after exposure to $\mathrm{CO}_{2} / \mathrm{H}_{2}(3: 1)$ at $230{ }^{\circ} \mathrm{C}$ and 5 bar for (a) PdGa@SiO 2 exposed (purple, top) and prior to exposure to reaction gases (gray, bottom); (b) $\mathrm{Pd} @ \mathrm{SiO}_{2}$ exposed (green, top) and prior to exposure to reaction gases (gray, bottom). Reaction time: $12 \mathrm{~h}$. spectra of the exposed PdGa@SiO 2 show signals at 49 ppm $\left({ }^{13} \mathrm{C}\right)$ and $3.6 \mathrm{ppm}\left({ }^{1} \mathrm{H}\right)$, consistent with the presence of surface methoxy groups (Supporting Information S12). In contrast, IR spectroscopy on $\mathrm{Pd} @ \mathrm{SiO}_{2}$ after treatment with $\mathrm{H}_{2} / \mathrm{CO}_{2}$ at $230{ }^{\circ} \mathrm{C}$ and 5 bar shows exclusively peaks at 2091 and $1964 \mathrm{~cm}^{-1}$, assigned to linear and bridged $\mathrm{CO}$ species (vide supra, Figure 1c), suggesting that strongly bound carbonyl species may suppress the formation of $\mathrm{CH}_{3} \mathrm{OH}$ on $\mathrm{Pd} @ \mathrm{SiO}_{2}$. In the corresponding experiment using $\mathrm{H}_{2} /{ }^{13} \mathrm{CO}_{2}$, only a very weak signal was observed in the CP-MAS spectrum at $49 \mathrm{ppm}$ (Supporting Information S12), indicating a very low concentration of surface methoxy groups.

To have a better understanding of the reaction intermediates at play under reaction conditions, operando DRIFTS on the $\mathrm{PdGa} @ \mathrm{SiO}_{2}$ catalyst was performed. Under a flow of $\mathrm{H}_{2} / \mathrm{CO}_{2}$ (3:1) at 20 bar and $230{ }^{\circ} \mathrm{C}$, at steady-state, bands assigned to $\mathrm{C}-\mathrm{H}$ stretching modes at 2960, 2920, and $2860 \mathrm{~cm}^{-1}$ are observed (Figure 5a). The intense bands at 2960 and 2860 $\mathrm{cm}^{-1}$ are assigned to methoxy species, while the weak band at $2920 \mathrm{~cm}^{-1}$ is assigned to bidentate formate species, consistent with earlier literature. ${ }^{19}$ Note that a second peak typically observed for bound formate species, at $\sim 2860 \mathrm{~cm}^{-1}$, is obscured by the dominant methoxy band (vide infra). Between 2200 and $1200 \mathrm{~cm}^{-1}$ (Figure 5b), three kinetically distinct bands are observed, with maxima at 2085, 1920, and 1588 $\mathrm{cm}^{-1}$, which are assigned to terminal $\mathrm{CO}$ bound to $\mathrm{Pd}\left(\mu_{1^{-}}\right.$ $\left.\mathrm{CO}_{\mathrm{Pd}}\right)$, bridging $\mathrm{CO}$ species bound to $\mathrm{Pd}\left(\mu_{\mathrm{n}}-\mathrm{CO}_{\mathrm{Pd}}\right)$, and the OCO asymmetric stretch of formate species bound to metallic sites, respectively. ${ }^{37}$ In contrast to observations from ex situ experiments, both surface carbonyl species and formate species are observed in reaction conditions. Consistent with observations from ex situ experiments, methoxy species are the dominant surface oxygenate species.

To probe the relevance of the observed surface species, we then turned to transient experiments (Figure 5c,d). MCR analysis of switching experiments, between $\mathrm{CO}_{2} / \mathrm{He}(1: 3)$ and $\mathrm{H}_{2} / \mathrm{He}(3: 1)$ at 20 bar and $230{ }^{\circ} \mathrm{C}$, reveals three distinct species in the $\mathrm{C}-\mathrm{H}$ stretching region, assigned to formate and two kinetically distinguishable methoxy species. In addition, the evolution of the bound terminal carbonyl species is observed. In $\mathrm{CO}_{2} / \mathrm{He}$, a rapid buildup of methoxy and terminally bound carbonyl species is observed, alongside a drop in the relative concentration of formate species. When switched to $\mathrm{H}_{2} / \mathrm{He}$, the concentration of methoxy species and carbonyl species falls rapidly, while the concentration of formate increases, with a concomitant increase in methanol formation (Supporting Information S13). These data support that the formation of methanol from methoxy surface species likely involves $\mathrm{H}_{2}$. In sum, both methoxy and carbonyl species are preferentially stabilized at the catalyst surface under $\mathrm{CO}_{2}$ rich conditions, while a greater fraction of bound formate species are observed in $\mathrm{H}_{2}$-rich conditions. The observation that surface formate concentrations are inversely correlated with the concentrations of methoxy and carbonyl species highlights the facile interchange between the two species and the dynamic nature of this catalyst.

\section{Proposed Role of Ga and Implications for Mechanism}

Both DRIFTS and XAS indicate that PdGa@SiO 2 is a dynamic catalytic system, where the chemical state of $\mathrm{Ga}$ and the observed surface intermediates are highly dependent on the chemical potential of the gas phase. Under $\mathrm{H}_{2}$-rich conditions, an increased proportion of $\mathrm{Ga}^{0}$ is observed by XAS, with a 
(a)

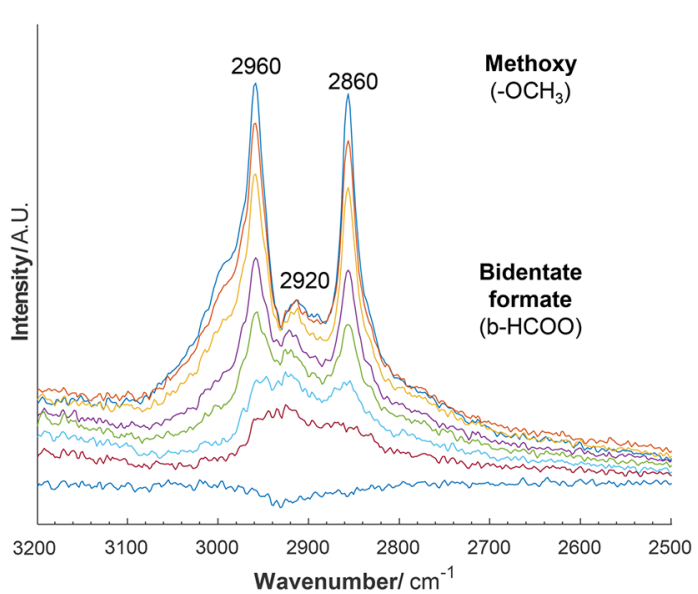

(c)

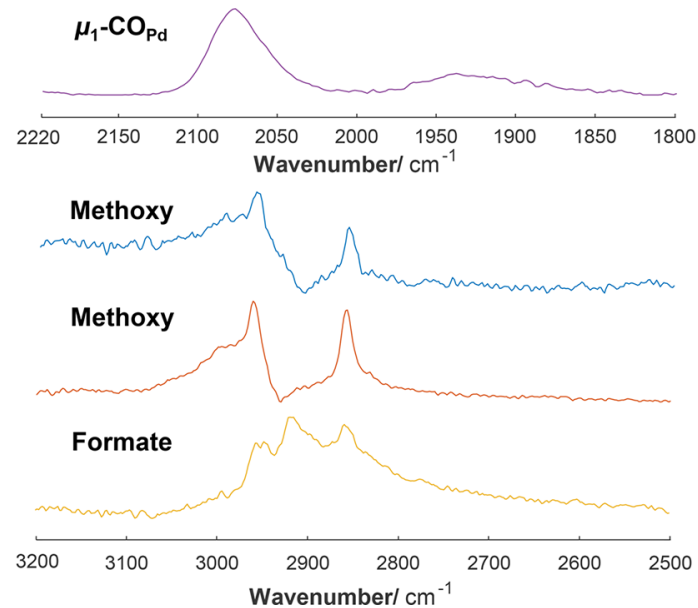

(b)

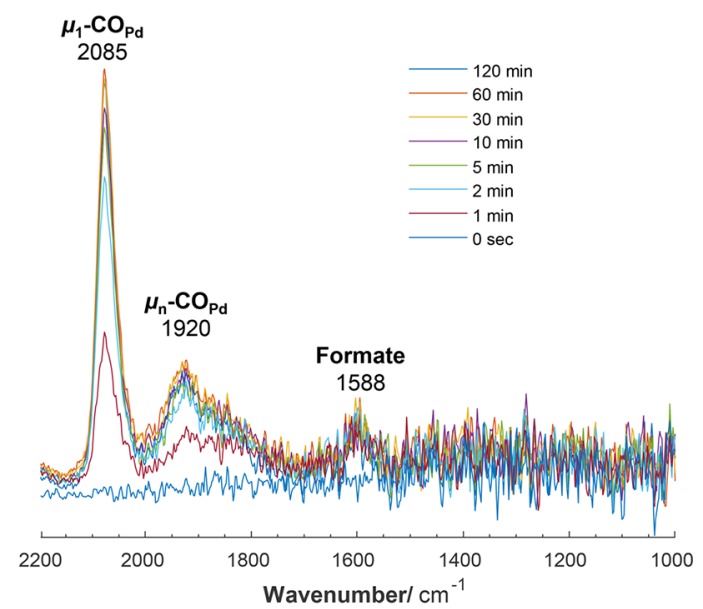

(d)

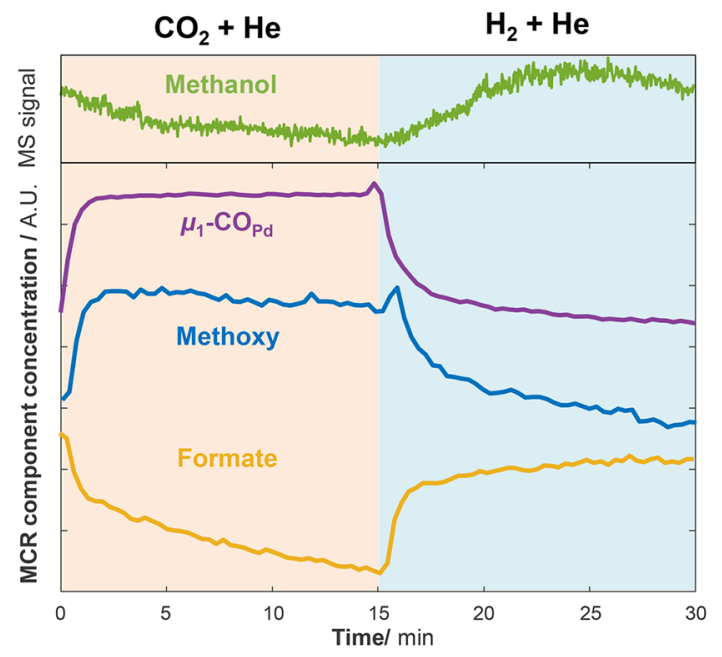

Figure 5. Operando DRIFTS spectra for (a, b) PdGa@SiO ${ }_{2}$ under $\mathrm{H}_{2} / \mathrm{CO}_{2}$ at steady state $\left(3: 1,20\right.$ bar, $\left.230{ }^{\circ} \mathrm{C}\right)$; (c) $\mathrm{MCR}$-resolved component profiles, and (d) MCR-resolved concentrations for PdGa@SiO ${ }_{2}$ under both $\mathrm{CO}_{2} / \mathrm{He}(1: 3)$ and $\mathrm{H}_{2} / \mathrm{He}$ (3:1). Conditions: 20 bar, $230{ }^{\circ} \mathrm{C}$.

concomitant emergence of formate species according to IR, which could indicate that formate surface species are preferentially stabilized by metallic sites, as previously proposed in the literature. ${ }^{38}$ In contrast, under $\mathrm{CO}_{2}$-rich conditions, an increased proportion of tetracoordinate $\mathrm{Ga}^{\mathrm{III}}$ is observed, alongside an increase in surface methoxy species, which are most likely stabilized by the $\mathrm{Ga}^{\mathrm{III}}$ species. This change of preponderant surface intermediates as a function of chemical potential, the low abundance (and stability) of formate species, and the high methanol selectivity at high conversion for this $\mathrm{PdGa} @ \mathrm{SiO}_{2}$ catalyst contrasts what is observed for $\mathrm{Cu} / \mathrm{ZrO}_{2}$ and related materials, where formates are invariably observed as stable surface adsorbates and methanol selectivity deteriorates with increasing conversion. Furthermore, it has been shown that the over stabilization of formate intermediates, clearly observed for $\mathrm{Cu} / \mathrm{Al}_{2} \mathrm{O}_{3}$, leads to the formation of methyl formate with increasing $\mathrm{CO}_{2}$ conversion (high methanol concentrations), which has been shown to decompose into methanol and $\mathrm{CO}$ under these conditions, thus decreasing the methanol selectivity. ${ }^{39}$ Hence, the lower stability of formate intermediates is likely linked to the higher observed methanol selectivity at an elevated conversion for $\mathrm{PdGa} @ \mathrm{SiO}_{2}$ catalysts. These results support that an efficient methanol synthesis from $\mathrm{CO}_{2}$ should involve a fast conversion of $\mathrm{CO}_{2}$ to formate, formate to methoxy intermediates, before formation and desorption of methanol.
Overall, the results discussed above could indicate that the ease of alloying-dealloying combined with the correlation between this phenomenon and the detection/stabilization of formate intermediates that the efficient alloying-dealloying process in this highly dynamic PdGa catalyst could be at the origin of its improved methanol activity and selectivity at higher $\mathrm{CO}_{2}$ conversion, since it would avoid an accumulation of formate intermediates and increase the rate of methanol formation.

\section{CONCLUSIONS}

In summary, $\mathrm{PdGa} @ \mathrm{SiO}_{2}$, prepared via SOMC using a tailored traceless Pd molecular precursor and a Ga-doped silica surface, is a highly selective and active catalyst for the hydrogenation of $\mathrm{CO}_{2}$ to $\mathrm{CH}_{3} \mathrm{OH}$, displaying activity an order of magnitude greater than the benchmark $\mathrm{Cu}$-based systems. In contrast to previously reported Pd-based systems, the $\mathrm{CH}_{3} \mathrm{OH}$ selectivity is high (ca. 80\%), and it does not decrease markedly at a higher conversion, suggesting that the use of a gallium-doped silica support containing exclusively isolated $\mathrm{G} \mathrm{a}^{\mathrm{III}}$ sites prevents the formation of larger $\mathrm{Ga}_{2} \mathrm{O}_{3}$ domains, which are known to promote RWGS. Analysis of the reduction process by XASTPR indicates that the PdGa alloy is formed through a gradual intercalation of $\mathrm{Ga}$ to $\mathrm{Pd}$ nanoparticles at elevated temperatures.

A study of the material under reaction conditions reveals that, while partial oxidation of $\mathrm{Ga}^{0}$ occurs, the $\mathrm{Ga}^{\mathrm{III}}$ species are 
exclusively tetracoordinate Ga sites. IR and NMR experiments allow the detection of surface-stabilized methoxy groups on $\mathrm{PdGa} @ \mathrm{SiO}_{2}$. An in situ study of $\mathrm{PdGa} @ \mathrm{SiO}_{2}$, by XAS, indicates that there are facile redox processes enabling the transformation between $\mathrm{Ga}^{0} / \mathrm{Ga}^{\mathrm{III}}$ under $\mathrm{CO}_{2}$ hydrogenation conditions, while the observed reaction intermediates, probed by operando DRIFTS, show a similar dependence on the gasphase composition. Transient experiments reveal the presence of both methoxy and formate species under reaction conditions, with the two surface species having inversely proportional concentrations. These observations highlight the subtle role of dynamic dealloying/realloying processes and how this can be exploited to generate highly active and selective catalytic systems. Further studies into the subtle interplay between the $\mathrm{Pd} / \mathrm{Ga}$ and $\mathrm{Pd} / \mathrm{Ga}^{\mathrm{III}} \mathrm{O}_{x}$ are currently underway, with the goal to understand the origin of the observed synergistic behavior between $\mathrm{Pd}$ and $\mathrm{Ga}$; other research efforts are directed at exploring the general applicability of this approach toward the formation of oxidesupported PdM nanoparticles and their application in selective hydrogenation reactions.

\section{EXPERIMENTAL SECTION}

\section{Synthesis of $\mathrm{Pd}(\mathrm{COD}) \mathrm{Me}\left(\mathrm{OSi}(\mathrm{OtBu})_{3}\right)$}

$\mathrm{Pd}(\mathrm{COD}) \mathrm{MeCl}(1.00 \mathrm{~g}, 3.77 \mathrm{mmol})$ was dissolved in toluene ( 80 $\mathrm{mL})$. To this was added a solution of $\mathrm{NaOSi}(\mathrm{O} t \mathrm{Bu})_{3}(1.08 \mathrm{~g}, 3.77$ $\mathrm{mmol})$ in toluene $(20 \mathrm{~mL})$, followed by successive washings of the reaction vessel $(2 \times 10 \mathrm{~mL})$. The reaction mixture was stirred, at room temperature, for $16 \mathrm{~h}$. The solvent was removed under reduced pressure to yield a dark solid. The remaining solid was washed with $\mathrm{Et}_{2} \mathrm{O}(3 \times 10 \mathrm{~mL})$, and the combined washings were concentrated under reduced pressure to yield a white crystalline solid. The solid was dissolved in $\mathrm{CH}_{2} \mathrm{Cl}_{2}(10 \mathrm{~mL})$ and cooled to $-40{ }^{\circ} \mathrm{C}$ to yield a small amount of white crystals. The reaction mixture was filtered over diatomaceous earth, and the supernatant was collected and concentrated under reduced pressure to yield a yellow solid. The solid was dissolved in pentane $(3 \mathrm{~mL})$ and cooled to $-40{ }^{\circ} \mathrm{C}$ overnight, to yield colorless rhombohedral crystals. Successive recrystallizations yielded $1.16 \mathrm{~g}$ of product (62\% yield).

\section{Synthesis of Pd(COD)Me@Ga@SiO $2-700$}

To a suspension of $\mathrm{Ga} @ \mathrm{SiO}_{2}(1.000 \mathrm{~g})$ in $\mathrm{C}_{6} \mathrm{H}_{6}(20 \mathrm{~mL})$ was added a clear solution of $\mathrm{Pd}(\mathrm{COD}) \mathrm{Me}\left(\mathrm{OSi}(\mathrm{O} t \mathrm{Bu})_{3}\right)(78.9 \mathrm{mg}, 0.16 \mathrm{mmol})$ in $\mathrm{C}_{6} \mathrm{H}_{6}(10 \mathrm{~mL})$. The suspension was stirred for $1 \mathrm{~h}$ at $25^{\circ} \mathrm{C}$. After it was stirred, the material was filtered, rinsed with $\mathrm{C}_{6} \mathrm{H}_{6}(3 \times 7 \mathrm{~mL})$, and dried under under high vacuum $\left(10^{-5} \mathrm{mbar}\right)$. Isobutene (1.9 equiv) was identified as the side product of the reaction.

\section{Synthesis of PdGa@SiO $2-700$}

To a glass flow reactor containing a medium porosity glass frit was added Pd(COD)Me@Ga@SiO $(0.773$ g). The flow reactor was evacuated $\left(10^{-5}\right.$ mbar $)$ and then filled with $\mathrm{H}_{2}$. The reactor was subsequently heated to $500{ }^{\circ} \mathrm{C}\left(5^{\circ} \mathrm{C} \mathrm{min}{ }^{-1}\right)$ while maintaining a flow of $\mathrm{H}_{2}(960 \mathrm{mbar}(\mathrm{a}))$. After $12 \mathrm{~h}$ of heating, the reactor was evacuated $\left(10^{-5} \mathrm{mbar}\right)$, while still hot, yielding a dark solid material.

\section{General Considerations}

Unless otherwise indicated, all manipulations were undertaken using conventional air-free techniques (argon). All solvents were purified by a solvent purification system (SPS) or by drying followed by distillation and stored over activated molecular sieves. $[\mathrm{Mg}$ $\left.\left(\mathrm{CH}_{2} \mathrm{Ph}\right)_{2}(\mathrm{THF})_{2}\right], \quad \mathrm{Pd}(\mathrm{COD}) \mathrm{Cl}_{2}, \mathrm{Ga}\left(\mathrm{OSi}(\mathrm{O} t \mathrm{Bu})_{3}\right)_{3}(\mathrm{THF})$, and $\mathrm{HOSi}(\mathrm{O} t \mathrm{Bu})_{3} \quad(\mathrm{THF}=$ tetrahydrofuran) were synthesized as described in earlier literature. ${ }^{29,40-42}$ Silica (Aerosil Degussa, 200 $\mathrm{m}^{2} \mathrm{~g}^{-1}$ ) was compacted with deionized water, dried at $100{ }^{\circ} \mathrm{C}$ for $7 \mathrm{~d}$, crushed, and sieved $(250-400 \mu \mathrm{m})$ for easier handling. Silica-700 $\left(\mathrm{SiO}_{2-700}\right)$ was calcined at $500{ }^{\circ} \mathrm{C}$ in air for $12 \mathrm{~h}$, allowed to return to room temperature, and treated under high vacuum $\left(10^{-5} \mathrm{mbar}\right)$ at
$500{ }^{\circ} \mathrm{C}$ for $12 \mathrm{~h}\left(\right.$ ramp: $5{ }^{\circ} \mathrm{C} \mathrm{min}{ }^{-1}$ ) and then at $700{ }^{\circ} \mathrm{C}$ for $24 \mathrm{~h}$ (ramp: $1.7^{\circ} \mathrm{C} \mathrm{min}^{-1}$ ).

Attenuated total reflectance (ATR) IR spectra were recorded inside an Ar-filled glovebox on a Bruker FT-IR Alpha spectrometer. Transmission-IR were recorded on Bruker FT-IR Alpha spectrometer or a Nicolet 6700 FTIR spectrophotometer. Spectra are normalized to the $\mathrm{Si}-\mathrm{O}-\mathrm{Si}$ overtone peak maximum at $1868 \mathrm{~cm}^{-1}$ for all materials. Solution NMR spectra were obtained on BrukerR DRX 300 spectrometer (7.05 T, Larmor Frequency: $300 \mathrm{MHz}\left({ }^{1} \mathrm{H}\right), 75.5$ $\left.\mathrm{MHz}\left({ }^{13} \mathrm{C}\right)\right) .{ }^{1} \mathrm{H}$ and ${ }^{13} \mathrm{C}$ chemical shifts are referenced relative to residual solvent peaks. ${ }^{43}$ Solid-state NMR spectra of grafted samples were recorded on a Bruker $400 \mathrm{MHz}$ NMR spectrometer using a double-resonance 4 or $3.2 \mathrm{~mm}$ probe. Single-crystal XRD was performed on a Bruker APEX-II CCD diffractometer, and structures were solved with the olex2.solve structure solution program $^{44}$ using Charge Flipping and refined with the ShelXL ${ }^{45}$ refinement package using Least Squares minimization. Particle size estimations were obtained by transmission electron microscopy (JEOL JEM-1400 Plus microscope). Energy-dispersive $\mathrm{X}$-ray mapping was measured on a Talos F200 X microscope. XAS measurements were performed at the $\mathrm{Pd}$ and Ga K edges at the SuperXAS beamline at SLS (PSI). The program package Demeter was used for the analysis of EXAFS. ${ }^{46}$ For operando DRIFTS experiments, a custom-made high-pressure reaction cell was mounted in a Harrick Praying Mantis diffuse reflection (DRIFTS) accessory. The spectra were collected using a Thermo Scientific Nicolet 6700 FT-IR spectrometer. The outlet gas stream was analyzed by a Pfeiffer OmniStar GSD 300C mass spectrometer.

$\mathrm{CO}_{2}$ hydrogenation rates were measured at $230{ }^{\circ} \mathrm{C}$ at differential conversions $(<10 \%)$ on all samples. Samples were loaded in an argonfilled glovebox. Samples were treated at $300{ }^{\circ} \mathrm{C}$ in 5:1 $\mathrm{H}_{2} / \mathrm{N}_{2}(60$ $\mathrm{sccm}, 1 \mathrm{bar}$ ) for $1 \mathrm{~h}$ before being cooled to the reaction temperature $\left(230{ }^{\circ} \mathrm{C}\right.$ in $\mathrm{N}_{2}$ flow $\left(50 \mathrm{sccm}, 1\right.$ bar)), after which, $\mathrm{CO}_{2}, \mathrm{H}_{2}$, and $\mathrm{Ar}$ (1:3:1) were introduced, and the reactor was pressurized (25 bar). The reactor pressure was maintained by a back-pressure regulator (Bronkhorst EL-PRESS). Gas flow rates were screened in the range from 100 to $6 \mathrm{sccm}$. Reactant and product concentrations in the reactant and effluent streams were measured by online gas chromatography (Agilent 7890 N GC). Product selectivity is defined on a per-carbon basis. Intrinsic formation rates (i.e., rate at zero contact time) are obtained by using a second-order polynomial fit on the experimental data and extrapolating to zero residence time.

Experimental procedures, purification procedures for commercial chemicals, instrument specifications, and characterization data are covered in greater detail in the Supporting Information.

\section{ASSOCIATED CONTENT}

\section{Supporting Information}

The Supporting Information is available free of charge at https://pubs.acs.org/doi/10.1021/jacsau.1c00021.

Complete experimental procedures, general considerations, spectroscopic methods, and associated data (PDF)

Crystallographic data file for 1 (CCDC Deposition No. 2007107) (CIF)

\section{AUTHOR INFORMATION}

\section{Corresponding Author}

Christophe Copéret - Department of Chemistry and Applied Biosciences, ETH Zürich, CH-8093 Zurich, Switzerland; (1) orcid.org/0000-0001-9660-3890; Email: ccoperet@ ethz.ch 


\section{Authors}

Scott R. Docherty - Department of Chemistry and Applied Biosciences, ETH Zürich, CH-8093 Zurich, Switzerland; (1) orcid.org/0000-0002-8605-3669

Nat Phongprueksathat - Catalysis Engineering, Department of Chemical Engineering, Delft University of Technology, 2629 HZ Delft, The Netherlands; O orcid.org/0000-00034225-8205

Erwin Lam - Department of Chemistry and Applied Biosciences, ETH Zürich, CH-8093 Zurich, Switzerland

Gina Noh - Department of Chemistry and Applied Biosciences, ETH Zürich, CH-8093 Zurich, Switzerland; (1) orcid.org/0000-0003-4717-5767

Olga V. Safonova - Paul Scherrer Institute, CH-5232 Villigen, Switzerland; 이이이.org/0000-0002-6772-1414

Atsushi Urakawa - Catalysis Engineering, Department of Chemical Engineering, Delft University of Technology, 2629 HZ Delft, The Netherlands; 10 orcid.org/0000-0001-77784008

Complete contact information is available at: https://pubs.acs.org/10.1021/jacsau.1c00021

\section{Author Contributions}

All authors have given approval to the final version of the manuscript.

Notes

The authors declare no competing financial interest.

\section{ACKNOWLEDGMENTS}

S.D., N.P., O.V.S., A.U., and C.C.H. thank the Swiss National Science Foundation (Grant Nos. 200021_169134 and CRSII5_183495) for funding. Part of this research was also funded by the SCCER Heat and Energy Storage program (InnoSuisse). The authors acknowledge J. Alfke, C. P. Gordon, and D. Trummer for assistance with XAS, SS-NMR, and X-ray crystallography, respectively. The authors thank L. Rochlitz and Dr X. Huang for recording TEM carried out at ScopeM. The authors also thank PSI SuperXAS for beamtime and provision of $\mathrm{Ga}^{0}$ and $\mathrm{Pd}^{0}$ reference materials.

\section{REFERENCES}

(1) Kondratenko, E. V.; Mul, G.; Baltrusaitis, J.; Larrazábal, G. O.; Pérez-Ramírez, J. Status and Perspectives of $\mathrm{CO}_{2}$ Conversion into Fuels and Chemicals by Catalytic, Photocatalytic and Electrocatalytic Processes. Energy Environ. Sci. 2013, 6 (11), 3112-3135.

(2) Goeppert, A.; Czaun, M.; Jones, J.-P.; Surya Prakash, G. K.; Olah, G. A. Recycling of Carbon Dioxide to Methanol and Derived Products - Closing the Loop. Chem. Soc. Rev. 2014, 43 (23), 79958048.

(3) Olah, G. A. Towards Oil Independence Through Renewable Methanol Chemistry. Angew. Chem., Int. Ed. 2013, 52 (1), 104-107. (4) Álvarez, A.; Bansode, A.; Urakawa, A.; Bavykina, A. V.; Wezendonk, T. A.; Makkee, M.; Gascon, J.; Kapteijn, F. Challenges in the Greener Production of Formates/Formic Acid, Methanol, and DME by Heterogeneously Catalyzed $\mathrm{CO}_{2}$ Hydrogenation Processes. Chem. Rev. 2017, 117 (14), 9804-9838.

(5) Jiang, X.; Nie, X.; Guo, X.; Song, C.; Chen, J. G. Recent Advances in Carbon Dioxide Hydrogenation to Methanol via Heterogeneous Catalysis. Chem. Rev. 2020, 120 (15), 7984-8034.

(6) Kasatkin, I.; Kurr, P.; Kniep, B.; Trunschke, A.; Schlögl, R. Role of Lattice Strain and Defects in Copper Particles on the Activity of $\mathrm{Cu} / \mathrm{ZnO} / \mathrm{Al}_{2} \mathrm{O}_{3}$ Catalysts for Methanol Synthesis. Angew. Chem., Int. Ed. 2007, 46 (38), 7324-7327.
(7) Chinchen, G. C.; Denny, P. J.; Jennings, J. R.; Spencer, M. S.; Waugh, K. C. Synthesis of Methanol: Part 1. Catalysts and Kinetics. Appl. Catal. 1988, 36, 1-65.

(8) Bart, J. C. J.; Sneeden, R. P. A. Copper-Zinc Oxide-Alumina Methanol Catalysts Revisited. Catal. Today 1987, 2 (1), 1-124.

(9) Schild, C.; Wokaun, A.; Baiker, A. On the Hydrogenation of CO and $\mathrm{CO}_{2}$ over Copper/Zirconia and Palladium/Zirconia Catalysts. Fresenius' J. Anal. Chem. 1991, 341 (5), 395-401.

(10) Fisher, I. A.; Woo, H. C.; Bell, A. T. Effects of Zirconia Promotion on the Activity of $\mathrm{Cu} / \mathrm{SiO}_{2}$ for Methanol Synthesis from $\mathrm{CO} / \mathrm{H}_{2}$ and $\mathrm{CO}_{2} / \mathrm{H}_{2}$. Catal. Lett. 1997, 44 (1), 11-17.

(11) Larmier, K.; Liao, W.-C.; Tada, S.; Lam, E.; Verel, R.; Bansode, A.; Urakawa, A.; Comas-Vives, A.; Copéret, C. $\mathrm{CO}_{2}$-to-Methanol Hydrogenation on Zirconia-Supported Copper Nanoparticles: Reaction Intermediates and the Role of the Metal-Support Interface. Angew. Chem., Int. Ed. 2017, 56 (9), 2318-2323.

(12) Sahibzada, M.; Metcalfe, I. S.; Chadwick, D. Methanol Synthesis from $\mathrm{CO} / \mathrm{CO}_{2} / \mathrm{H}_{2}$ over $\mathrm{Cu} / \mathrm{ZnO} / \mathrm{Al}_{2} \mathrm{O}_{3}$ at Differential and Finite Conversions. J. Catal. 1998, 174 (2), 111-118.

(13) Collins, S. E.; Baltanás, M. A.; Bonivardi, A. L. An Infrared Study of the Intermediates of Methanol Synthesis from Carbon Dioxide over $\mathrm{Pd} / \beta-\mathrm{Ga}_{2} \mathrm{O}_{3}$. J. Catal. 2004, 226, 410.

(14) Collins, S. E.; Delgado, J. J.; Mira, C.; Calvino, J. J.; Bernal, S.; Chiavassa, D. L.; Baltanás, M. A.; Bonivardi, A. L. The Role of Pd-Ga Bimetallic Particles in the Bifunctional Mechanism of Selective Methanol Synthesis via $\mathrm{CO}_{2}$ Hydrogenation on a $\mathrm{Pd} / \mathrm{Ga}_{2} \mathrm{O}_{3}$ Catalyst. J. Catal. 2012, 292, 90-98.

(15) Arana, J.; Homs, N.; Sales, J.; Fierro, J.L.G.; Ramirez de la Piscina, P. CO $/ \mathrm{CO}_{2}$ Hydrogenation and Ethylene Hydroformylation over Silica-Supported PdZn Catalysts. Catal. Lett. 2001, 72 (3), 183189.

(16) Ota, A.; Kunkes, E. L.; Kasatkin, I.; Groppo, E.; Ferri, D.; Poceiro, B.; Navarro Yerga, R. M.; Behrens, M. Comparative Study of Hydrotalcite-Derived Supported $\mathrm{Pd}_{2} \mathrm{Ga}$ and $\mathrm{PdZn}$ Intermetallic Nanoparticles as Methanol Synthesis and Methanol Steam Reforming Catalysts. J. Catal. 2012, 293, 27-38.

(17) Fiordaliso, E. M.; Sharafutdinov, I.; Carvalho, H. W. P.; Grunwaldt, J.-D.; Hansen, T. W.; Chorkendorff, I.; Wagner, J. B.; Damsgaard, C. D. Intermetallic $\mathrm{GaPd}_{2}$ Nanoparticles on $\mathrm{SiO}_{2}$ for Low-Pressure $\mathrm{CO}_{2}$ Hydrogenation to Methanol: Catalytic Performance and In Situ Characterization. ACS Catal. 2015, 5 (10), 58275836.

(18) Bowker, M. Methanol Synthesis from $\mathrm{CO}_{2}$ Hydrogenation. Chem CatChem 2019, 11 (17), 4238-4246.

(19) Manrique, R.; Rodríguez-Pereira, J.; Rincón-Ortiz, S. A.; BravoSuárez, J. J.; Baldovino-Medrano, V. G.; Jiménez, R.; Karelovic, A. The Nature of the Active Sites of $\mathrm{Pd}-\mathrm{Ga}$ Catalysts in the Hydrogenation of $\mathrm{CO}_{2}$ to Methanol. Catal. Sci. Technol. 2020, 10 (19), 6644-6658.

(20) Manrique, R.; Jiménez, R.; Rodríguez-Pereira, J.; BaldovinoMedrano, V. G.; Karelovic, A. Insights into the Role of $\mathrm{Zn}$ and $\mathrm{Ga}$ in the Hydrogenation of $\mathrm{CO}_{2}$ to Methanol over Pd. Int. J. Hydrogen Energy 2019, 44 (31), 16526-16536.

(21) Fujitani, T.; Saito, M.; Kanai, Y.; Watanabe, T.; Nakamura, J.; Uchijima, T. Development of an Active $\mathrm{Ga}_{2} \mathrm{O}_{3}$ Supported Palladium Catalyst for the Synthesis of Methanol from Carbon Dioxide and Hydrogen. Appl. Catal., A 1995, 125 (2), L199-L202.

(22) Oyola-Rivera, O.; Baltanás, M. A.; Cardona-Martínez, N. $\mathrm{CO}_{2}$ Hydrogenation to Methanol and Dimethyl Ether by $\mathrm{Pd}-\mathrm{Pd}_{2} \mathrm{Ga}$ Catalysts Supported over $\mathrm{Ga}_{2} \mathrm{O}_{3}$ Polymorphs. J. $\mathrm{CO}_{2}$ Util. 2015, 9, 815.

(23) García-Trenco, A.; White, E. R.; Regoutz, A.; Payne, D. J.; Shaffer, M. S. P.; Williams, C. K. Pd $\mathrm{Pd}_{2}$ Ga-Based Colloids as Highly Active Catalysts for the Hydrogenation of $\mathrm{CO}_{2}$ to Methanol. ACS Catal. 2017, 7 (2), 1186-1196.

(24) Lam, E.; Larmier, K.; Wolf, P.; Tada, S.; Safonova, O. V.; Copéret, C. Isolated $\mathrm{Zr}$ Surface Sites on Silica Promote Hydrogenation of $\mathrm{CO}_{2}$ to $\mathrm{CH}_{3} \mathrm{OH}$ in Supported Cu Catalysts. J. Am. Chem. Soc. 2018, 140 (33), 10530-10535. 
(25) Noh, G.; Docherty, S. R.; Lam, E.; Huang, X.; Mance, D.; Alfke, J. L.; Copéret, C. $\mathrm{CO}_{2}$ Hydrogenation to $\mathrm{CH}_{3} \mathrm{OH}$ on Supported $\mathrm{Cu}$ Nanoparticles: Nature and Role of $\mathrm{Ti}$ in Bulk Oxides vs Isolated Surface Sites. J. Phys. Chem. C 2019, 123 (51), 31082-31093.

(26) Noh, G.; Lam, E.; Alfke, J. L.; Larmier, K.; Searles, K.; Wolf, P.; Copéret, C. Selective Hydrogenation of $\mathrm{CO}_{2}$ to $\mathrm{CH}_{3} \mathrm{OH}$ on Supported $\mathrm{Cu}$ Nanoparticles Promoted by Isolated $\mathrm{Ti}^{\mathrm{IV}}$ Surface Sites on $\mathrm{SiO}_{2}$. ChemSusChem 2019, 12 (5), 968-972.

(27) Lam, E.; Noh, G.; Chan, K. W.; Larmier, K.; Lebedev, D.; Searles, K.; Wolf, P.; Safonova, O. V.; Copéret, C. Enhanced $\mathrm{CH}_{3} \mathrm{OH}$ Selectivity in $\mathrm{CO}_{2}$ Hydrogenation Using $\mathrm{Cu}$-Based Catalysts Generated via SOMC from Ga ${ }^{\text {III }}$ Single-Sites. Chem. Sci. 2020, 11, $7593-7598$.

(28) Copéret, C. Single-Sites and Nanoparticles at Tailored Interfaces Prepared via Surface Organometallic Chemistry from Thermolytic Molecular Precursors. Acc. Chem. Res. 2019, 52 (6), $1697-1708$.

(29) Searles, K.; Siddiqi, G.; Safonova, O. V.; Copéret, C. SilicaSupported Isolated Gallium Sites as Highly Active, Selective and Stable Propane Dehydrogenation Catalysts. Chem. Sci. 2017, 8 (4), 2661-2666.

(30) Zhao, B.; Pan, Y.; Liu, C. The Promotion Effect of $\mathrm{CeO}_{2}$ on $\mathrm{CO}_{2}$ Adsorption and Hydrogenation over $\mathrm{Ga}_{2} \mathrm{O}_{3}$. Catal. Today 2012, 194 (1), 60-64.

(31) Laurent, P.; Veyre, L.; Thieuleux, C.; Donet, S.; Copéret, C. From Well-Defined Pt(II) Surface Species to the Controlled Growth of Silica Supported Pt Nanoparticles. Dalt. Trans. 2013, 42 (1), 238248.

(32) Tew, M. W.; Miller, J. T.; van Bokhoven, J. A. Particle Size Effect of Hydride Formation and Surface Hydrogen Adsorption of Nanosized Palladium Catalysts: $\mathrm{L}_{3}$ Edge vs K Edge X-Ray Absorption Spectroscopy. J. Phys. Chem. C 2009, 113 (34), 15140-15147.

(33) Sheppard, N.; De La Cruz, C. The Reliability of Vibrational Spectroscopy as a Means of Identification of the Structures of Chemisorbed Species on Metal Surfaces: The Cases of CO, NO and $\mathrm{C}_{2}$ Hydrocarbon Surface Species. Catal. Today 2001, 70 (1-3), 3-13.

(34) Kovnir, K.; Armbrüster, M.; Teschner, D.; Venkov, T. V.; Szentmiklósi, L.; Jentoft, F. C.; Knop-Gericke, A.; Grin, Y.; Schlögl, R. In Situ Surface Characterization of the Intermetallic Compound PdGa - A Highly Selective Hydrogenation Catalyst. Surf. Sci. 2009, 603 (10), 1784-1792.

(35) Su, X.; Lin, W.; Cheng, H.; Zhang, C.; Li, Y.; Liu, T.; Zhang, B.; $\mathrm{Wu}$, Q.; Yu, X.; Zhao, F. PdGa/TiO 2 an Efficient Heterogeneous Catalyst for Direct Methylation of N-Methylaniline with $\mathrm{CO}_{2} / \mathrm{H}_{2}$. RSC Adv. 2016, 6 (105), 103650-103656.

(36) Nishi, K.; Shimizu, K.; Takamatsu, M.; Yoshida, H.; Satsuma, A.; Tanaka, T.; Yoshida, S.; Hattori, T. Deconvolution Analysis of Ga K-Edge XANES for Quantification of Gallium Coordinations in Oxide Environments. J. Phys. Chem. B 1998, 102 (50), 10190-10195.

(37) Sun, Q.; Chen, B. W. J.; Wang, N.; He, Q.; Chang, A.; Yang, C.M.; Asakura, H.; Tanaka, T.; Hülsey, M. J.; Wang, C.-H.; Yu, J.; Yan, N. Zeolite-Encaged Pd-Mn Nanocatalysts for $\mathrm{CO}_{2}$ Hydrogenation and Formic Acid Dehydrogenation. Angew. Chem., Int. Ed. 2020, 59 (45), 20183-20191.

(38) Corral-Pérez, J. J.; Bansode, A.; Praveen, C. S.; Kokalj, A.; Reymond, H.; Comas-Vives, A.; VandeVondele, J.; Copéret, C.; von Rohr, P. R.; Urakawa, A. Decisive Role of Perimeter Sites in SilicaSupported Ag Nanoparticles in Selective Hydrogenation of $\mathrm{CO}_{2}$ to Methyl Formate in the Presence of Methanol. J. Am. Chem. Soc. 2018, 140 (42), 13884-13891.

(39) Copéret, C.; Lam, E.; Corral-Pérez, J. J.; Larmier, K.; Noh, G.; Wolf, P.; Comas-Vives, A.; Urakawa, A. $\mathrm{CO}_{2}$ Hydrogenation on $\mathrm{Cu} /$ $\mathrm{Al}_{2} \mathrm{O}_{3}$ : Role of Metal/Support Interface in Driving Activity and Selectivity of a Bifunctional Catalyst. Angew. Chem., Int. Ed. 2019, 58 (39), 13989-13996.

(40) Drew, D.; Doyle, J. R.; Shaver, A. G. Cyclic Diolefin Complexes of Platinum and Palladium. In Inorganic Syntheses; John Wiley \& Sons, Ltd, 2007; pp 47-55. DOI: 10.1002/9780470132449.ch11.
(41) Sandoval, J. J.; Palma, P.; Álvarez, E.; Cámpora, J.; RodríguezDelgado, A. Mechanism of Alkyl Migration in Diorganomagnesium 2,6-Bis(Imino)Pyridine Complexes: Formation of Grignard-Type Complexes with Square-Planar $\mathrm{Mg}(\mathrm{II})$ Centers. Organometallics 2016, 35 (18), 3197-3204.

(42) Docherty, S. R.; Estes, D. P.; Copéret, C. Facile Synthesis of Unsymmetrical Trialkoxysilanols: $(\mathrm{RO})_{2}\left(\mathrm{R}^{\prime} \mathrm{O}\right) \mathrm{SiOH}$. Helv. Chim. Acta 2018, 101 (3), e1700298 DOI: 10.1002/hlca.201700298.

(43) Fulmer, G. R.; Miller, A. J. M.; Sherden, N. H.; Gottlieb, H. E.; Nudelman, A.; Stoltz, B. M.; Bercaw, J. E.; Goldberg, K. I. NMR Chemical Shifts of Trace Impurities: Common Laboratory Solvents, Organics, and Gases in Deuterated Solvents Relevant to the Organometallic Chemist. Organometallics 2010, 29 (9), 2176-2179.

(44) Bourhis, L. J.; Dolomanov, O. V.; Gildea, R. J.; Howard, J. A. K.; Puschmann, H. The Anatomy of a Comprehensive Constrained, Restrained Refinement Program for the Modern Computing Environment - Olex2 Dissected. Acta Crystallogr., Sect. A: Found. Adv. 2015, 71 (1), 59-75.

(45) Sheldrick, G. M. Crystal Structure Refinement with SHELXL. Acta Crystallogr., Sect. C: Struct. Chem. 2015, 71 (1), 3-8.

(46) Ravel, B.; Newville, M. ATHENA, ARTEMIS, HEPHAESTUS: Data Analysis for X-Ray Absorption Spectroscopy Using IFEFFIT. J. Synchrotron Radiat. 2005, 12 (4), 537-541. 